\title{
A molecular signature of dormancy in CD34+CD38- acute myeloid leukaemia cells
}

\author{
Mazin Gh. Al-Asadi ${ }^{1,2}$, Grace Brindle ${ }^{1}$, Marcos Castellanos ${ }^{3}$, Sean T. May ${ }^{3}$, Ken I. \\ Mills $^{4}$, Nigel H. Russell ${ }^{1,5}$, Claire H. Seedhouse ${ }^{1}$ and Monica Pallis ${ }^{5}$ \\ 'University of Nottingham, School of Medicine, Academic Haematology, Nottingham, UK \\ ${ }^{2}$ University of Basrah, College of Medicine, Basrah, Iraq \\ ${ }^{3}$ University of Nottingham, School of Biosciences, Nottingham, UK \\ ${ }^{4}$ Centre for Cancer Research and Cell Biology, Queen's University Belfast, Belfast, UK \\ ${ }^{5}$ Clinical Haematology, Nottingham University Hospitals, Nottingham, UK \\ Correspondence to: Claire H. Seedhouse, email: Claire.seedhouse@nottingham.ac.uk \\ Keywords: AML; dormancy; gene expression profiling \\ Received: September 19, $2017 \quad$ Accepted: November 14, $2017 \quad$ Published: November 30, 2017 \\ Copyright: Al-Asadi et al. This is an open-access article distributed under the terms of the Creative Commons Attribution License 3.0 \\ (CC BY 3.0), which permits unrestricted use, distribution, and reproduction in any medium, provided the original author and source \\ are credited.
}

\section{ABSTRACT}

Dormant leukaemia initiating cells in the bone marrow niche are a crucial therapeutic target for total eradication of acute myeloid leukaemia. To study this cellular subset we created and validated an in vitro model employing the cell line TF$1 a$, treated with Transforming Growth Factor $\beta 1$ (TGF $\beta 1$ ) and a mammalian target of rapamycin inhibitor. The treated cells showed decreases in total RNA, Ki-67 and CD71, increased aldehyde dehydrogenase activity, forkhead box 03A (FOX03A) nuclear translocation and growth inhibition, with no evidence of apoptosis or differentiation. Using human genome gene expression profiling we identified a signature enriched for genes involved in adhesion, stemness/inhibition of differentiation and tumour suppression as well as canonical cell cycle regulation. The most upregulated gene was the osteopontin-coding gene SPP1. Dormant cells also demonstrated significantly upregulated beta 3 integrin (ITGB3) and CD44, as well as increased adhesion to their ligands vitronectin and hyaluronic acid as well as to bone marrow stromal cells. Immunocytochemistry of bone marrow biopsies of AML patients confirmed the positive expression of osteopontin in blasts near the para-trabecular bone marrow, whereas osteopontin was rarely detected in mononuclear cell isolates. Unsupervised hierarchical clustering of the dormancy gene signature in primary acute myeloid leukaemia samples from the Cancer Genome Atlas identified a cluster enriched for dormancy genes associated with poor overall survival.

\section{INTRODUCTION}

Acute myeloid leukaemia (AML) is characterised by a high disease relapse rate despite initial induction of remission. The leukaemia-initiating cells (LIC) that survive chemotherapy are likely to be enriched for a dormant subpopulation within the bone marrow niche [1]. Dormancy is a non-proliferative state where cells stay outside the cell cycle but retain their proliferative potential, in contrast to the terminally non-proliferative differentiated cell. The study and characterization of dormant LICs could pave the way to their targeting and eradication, but the simple paradox that these rare dormant cells cannot be expanded for research without breaking their dormancy suggests that efforts need to be directed to establish experimental models of induced dormancy.

The crosstalk between LICs and the bone marrow (BM) niche in which they reside has been implicated 
in dormancy regulation. Leukaemia cells which are responsible for relapsed AML, similar to normal haematopoietic stem cells (HSCs), reside in a low perfusion microenvironment in the endosteal region of the bone marrow [2-4]. The scarcity of nutrients in the poorly-perfused niche is likely to contribute to leukaemia cell dormancy and resistance to chemotherapy. MTOR inhibition by rapamycin can be used to mimic shortage of nutrients $[5,6]$, and has been employed for the in vitro maintenance of haematopoietic stem cells [7]. Furthermore, it has been reported that mTORinhibited leukaemia cell lines [8] and prostatic cancer cells [9] showed features of dormancy and resistance to chemotherapy. TGF $\beta 1$ is strongly involved in the regulation of dormancy in normal undifferentiated HSC [10]. The addition of mTOR inhibition to TGF $\beta 1$ was reported to potentiate the inhibitory effect of TGF $\beta 1$ in transformed cells [11].

The current study aimed to exploit the above two key BM LIC niche characteristics - i.e. the abundance of TGF $\beta 1$ and shortage of nutrients, to establish an in vitro model that enables molecular characterization of dormant AML cells. Some AML clones are dependent on aberrant activation of the mTOR pathway for survival and hence sensitive to clinical mTOR inhibitors, but other clones are resistant [12], and in this study we characterise a cell line (TF-1a) which remained viable in the presence of rapamycin and in which we were able to exploit the dormancy-inducing physiological role of mTOR inhibition [13]. This work is a step towards the ultimate goal of finding molecular targets that might help to eradicate dormant LICs and hence prevent relapse.

\section{RESULTS}

\section{TGFß1 and mTOR pathway inhibition significantly impede TF-1a cell proliferation and induce features of dormancy and stemness without affecting cell viability or inducing cell differentiation}

TF-1a cells were cultured with $4 \mathrm{ng} / \mathrm{ml}$ TGF $\beta 1$ and/ or $100 \mathrm{nM}$ rapamycin. Clonogenic growth was inhibited by TGF $\beta 1$ or rapamycin individually, and the combination of the two agents blocked the formation of colonies ( $>95 \%$ inhibition, Figure 1A). Growth inhibition in suspension culture (Figure 1B) was accompanied by features of dormancy including an increase in the proportion of $\mathrm{Ki}$ 67 negative cells $(\mathrm{p}<0.01)$ (Figure $1 \mathrm{C})$ and a decrease in RNA, characteristic of dormant cells due to their low metabolic activity (Figure 1D). In addition, a significant decrease in the transferrin receptor and proliferation marker CD71 was evident (Figure 1E). TGF $\beta 1+$ rapamycin treatment showed no effect on the viability of TF-1a cells as determined by annexinV flow cytometry assay (Supplementary Figure 1), excluding cellular death as a possible explanation for the growth inhibition. The cellular potential to proliferate decreases in the haematopoietic cell hierarchy as cells differentiate. However, following conditioning with TGF $\beta 1$ and/or rapamycin, TF-1a cells maintained a primitive morphology with no signs of differentiation (Supplementary Figure 2). TGF $\beta 1$ is reported to upregulate the stem-like properties of HSC [14] and LIC [15], and AML cells with intermediate ALDH activity are reported to be highly represented in minimal residual disease AML samples [16]. TGF $\beta 1$ upregulated ALDH activity and surface CD34 expression in TF-1a cells. Of note, although CD34 expression ranges from negative to positive in untreated TF-1a cells the treated cells became $>90 \%$ CD34+ (Figure 1F and Supplementary Figure 3). Relocation of FOXO3a from cytoplasm to nucleus, suggestive of activation, was also seen (Figure 1F). Growth-inhibitory responses of KG-1a, Kasumi-3 and M0-91 cells to TGF $\beta 1$ were also measured as well as their CD34 and CD38 status (Supplementary Figure 3). The growth-inhibitory response to TGF $\beta 1$ noted in TF-1a cells compared to KG-1a and Kasumi-3 cells and the pronounced loss of Ki-67 in TF-1a after TGF $\beta 1$ treatment compared to Kasumi-3 and M0-91 cells supported its selection to model and characterize AML cell dormancy in the study.

\section{Molecular signature of TF-1a cells induced to dormancy}

Dormancy-induced TF-1a cells were subjected to molecular characterization by microarray analysis. Restricting the dormancy signature to genes upregulated or downregulated by at least 2 fold with false discovery rate (FDR)-adjusted $\mathrm{p}$ value $<0.05$, we found 240 upregulated genes and 136 downregulated genes in dormant TF-1a cells compared to their untreated (cycling) counterparts (Figure 2 and Supplementary Figure 4). A full list of the differentially regulated genes can be found in Supplementary Tables 1 and 2) and a copy of the complete results have been deposited in the gene expression omnibus database, (http://www.ncbi.nlm.nih. gov/geo/), reference GSE102483. As is clear from Figure 2 , TGF $\beta 1$ alone contributes much more strongly to gene upregulation than rapamycin, but the disparity is not as strong in downregulated genes.

Among the 240 differentially upregulated and 136 downregulated genes in dormant TF-1a cells, we identified canonical targets of TGFB1 and of mTOR inhibition (Supplementary Table 3). We found three biologically relevant groups of genes highly represented in the dormancy signature. These were adhesion-related, tumour suppressor and stemness / inhibition of differentiationrelated genes (Figure 3). The categories overlap: for example, amongst the adhesion related genes, ITGB3 [17] and CD44 [18] are also essential for the maintenance of leukaemia initiating cells. 


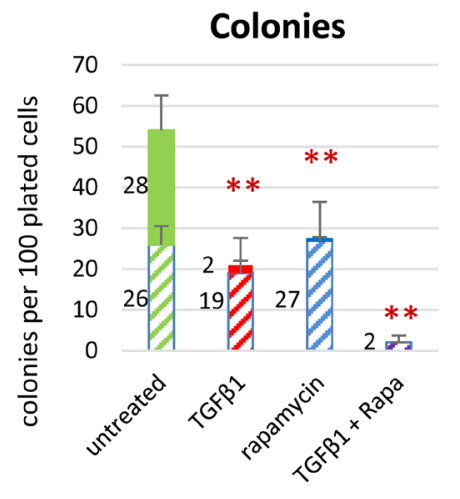

D
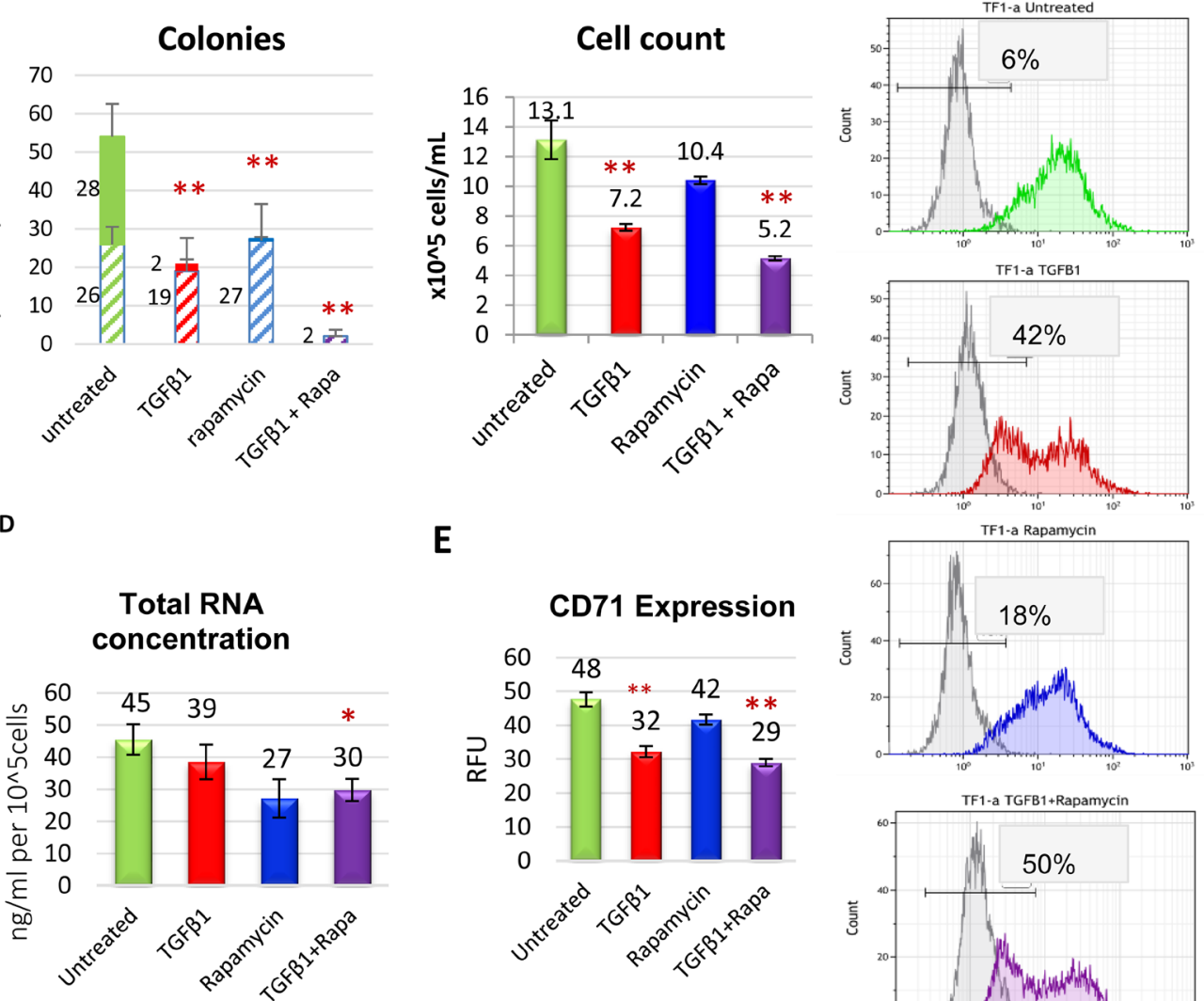

$\mathbf{E}$
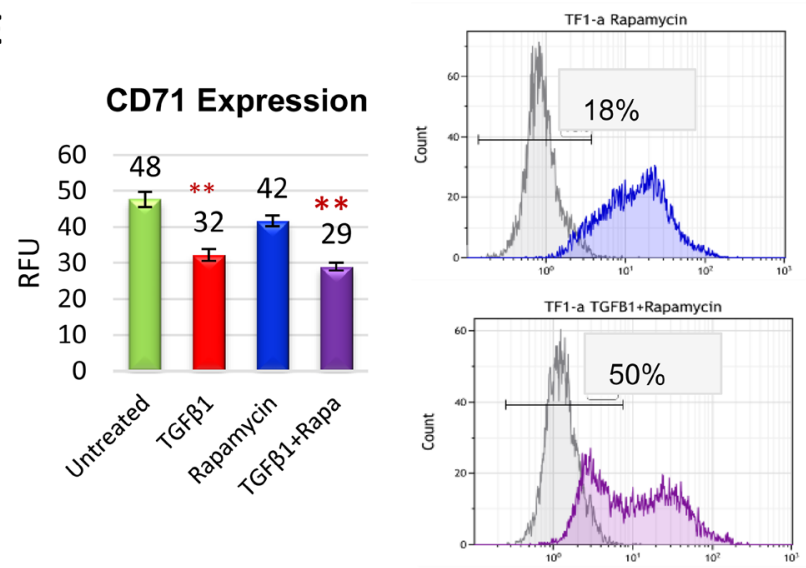

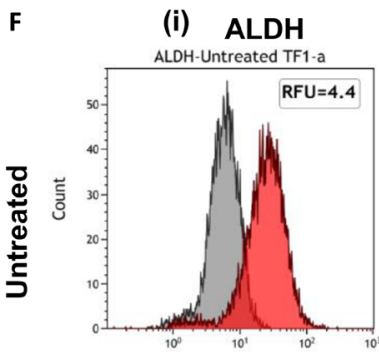

(ii) CD34
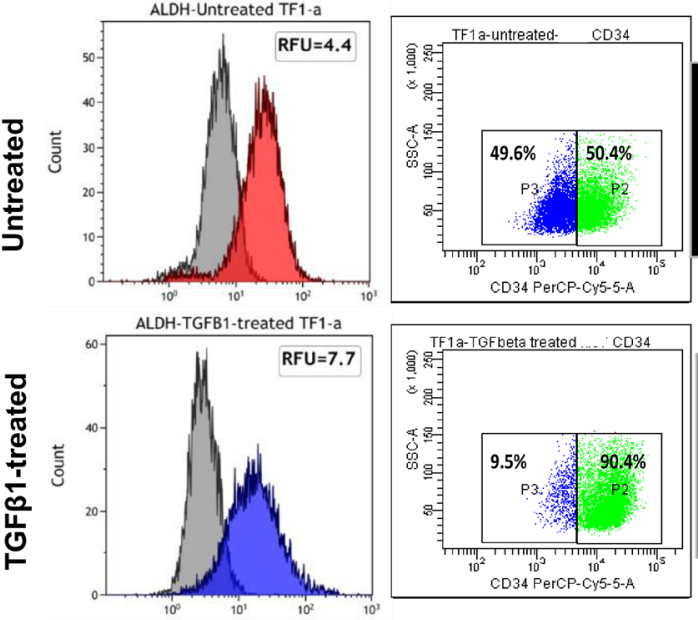

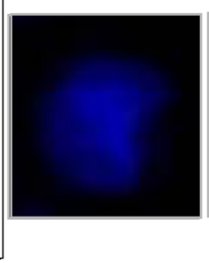

(iii) FOXO3a

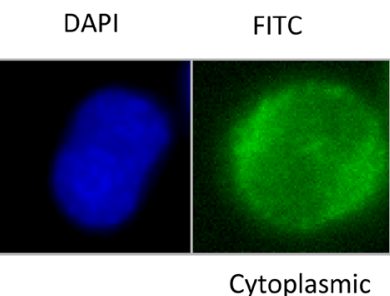

Merge
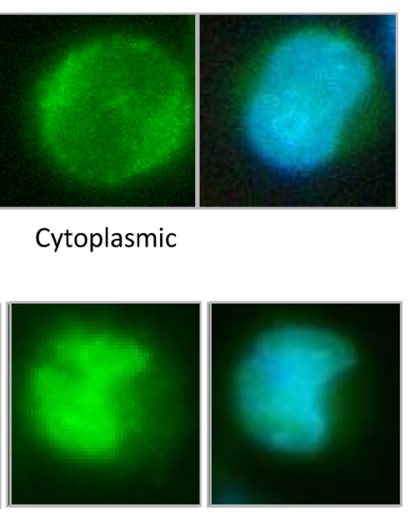

Nuclear

Figure 1: Dormancy induction in TF-1a cells. (A) Clonogenic assays were carried out in a methylcellulose-based medium (H4100 from Stem cell Technologies) using standard procedures, with TF-1a cells seeded at 200 cells per $100 \mu \mathrm{l}$ in triplicate in 96-well plates with 4ng/ml TGF $\beta 1$ and/or 100nM rapamycin. Large colonies (solid upper bars, $>50$ cells) and smaller colonies (striped lower bars, 20-50 cells) were counted after 6 days. (B) Inhibition of growth in suspension culture. Cells were seeded at a concentration of $2 \times 10^{\wedge} 5$ cells/ml and incubated for $72 \mathrm{hrs}$ with $4 \mathrm{ng} / \mathrm{ml}$ TGF $\beta 1$ and/or 100nM rapamycin before counting. (C) Cells were cultured for 3 days as in B: flow cytometric histograms of Ki-67 expression. Isotype control (grey histograms) are used as a reference to determine the percentage of Ki-67 negative cells. (D) Cells were cultured for 3 days as in B. Total RNA content was measured using a nanodrop. (E) Cells were cultured for 3 days as in B: surface CD71 expression measured by flow cytometry. (F) Modulation of stemness markers by TGF $\beta 1$ : ALDH (i), CD34 (ii) and FOXO3a (iii). In A, B, D and E, the columns represent mean $+/-\mathrm{SD}$ of three independent experiments $\left({ }^{*}: p<0.05 ;{ }^{* *}: p<0.01\right)$. In $\mathrm{C}$ and $\mathrm{F}$, the figures are representative examples of 3 biological replicates. 
Integrin and cell adhesion signalling pathways dominate the biological processes enriched in the molecular signature of dormant AML cells

To group the detected genes based on their gene ontology (GO) categories into relevant biological processes, gene enrichment analysis was performed (in Partek) using the Kyoto Encyclopaedia of Genes and Genomes (KEGG) database. Information was available on 195 of the 240 upregulated genes, and these mapped to 56 distinct biologically relevant groups (Supplementary Table
4). Among these, the integrin-mediated and cell adhesion signalling pathways showed the highest enrichment scores; 14.43 and 13.41 respectively ( $<<0.001$ for both). Confirmation of adhesion-related gene upregulation was obtained by quantitative PCR (Figure 4). Information on 100/136 downregulated genes was available and these were mapped to 46 significantly enriched distinct biologically relevant groups (Supplementary Table 5). Downregulated genes were dominated by alterations in metabolic pathways.

\section{A Upregulated genes}

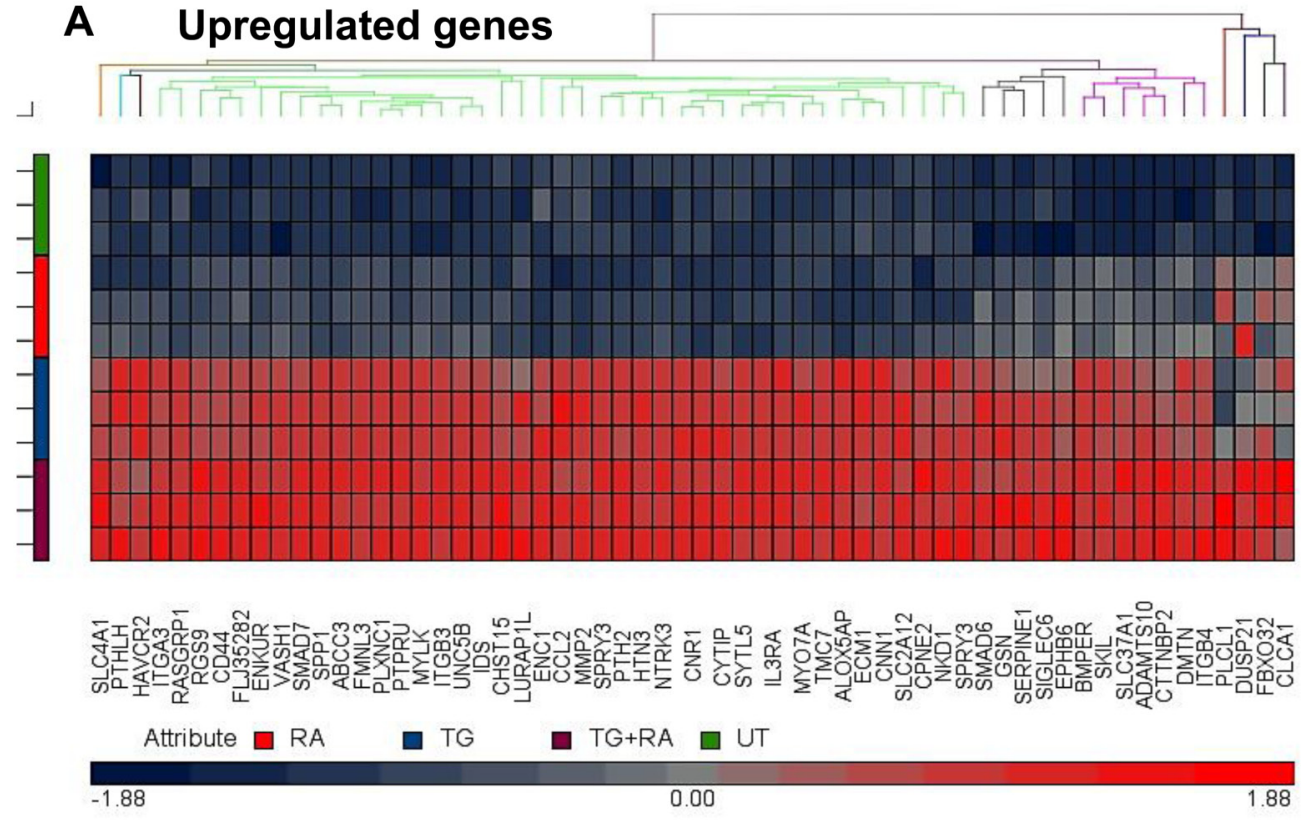

B Downregulated genes

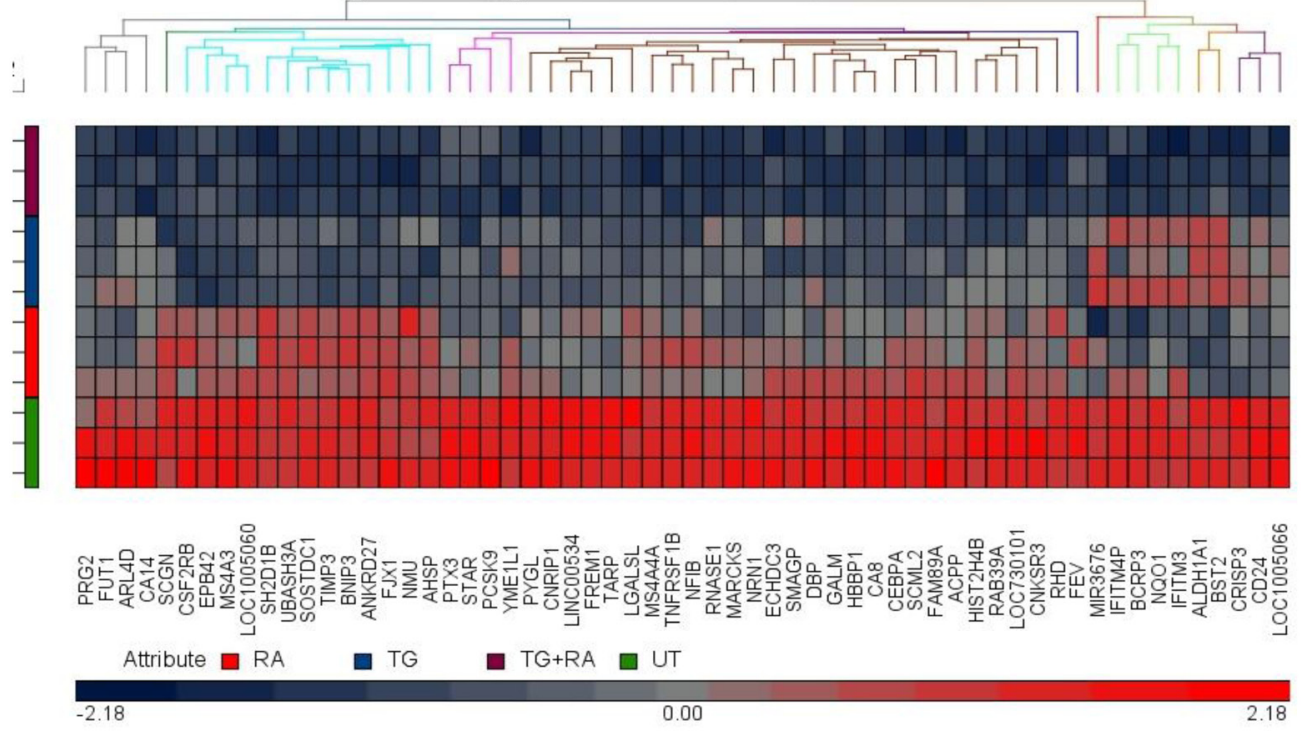

Figure 2: Heat maps of differentially regulated genes in dormant TF-1a cells. TF-1a cells were cultured for 3 days with $4 \mathrm{ng} / \mathrm{ml}$ TGF $\beta 1$ and/or 100nM rapamycin prior to gene expression profiling. The heat maps illustrate (A) The top 60 of the 240 most significantly upregulated genes and (B) the top 60 of the 136 most downregulated genes. UT: untreated; RA: rapamycin; TG: TGF $\beta 1$. 
Osteopontin is expressed in AML bone marrow and its expression is stimulated by TGF $\beta 1$ in primary samples

SPP1, the gene encoding osteopontin, showed the highest fold upregulation in our model. However levels (even though significantly upregulated) were low and attempts at protein detection in the model were unreliable. A meta-analysis of several studies indicates that serum osteopontin (OPN) is a marker of poor survival and a

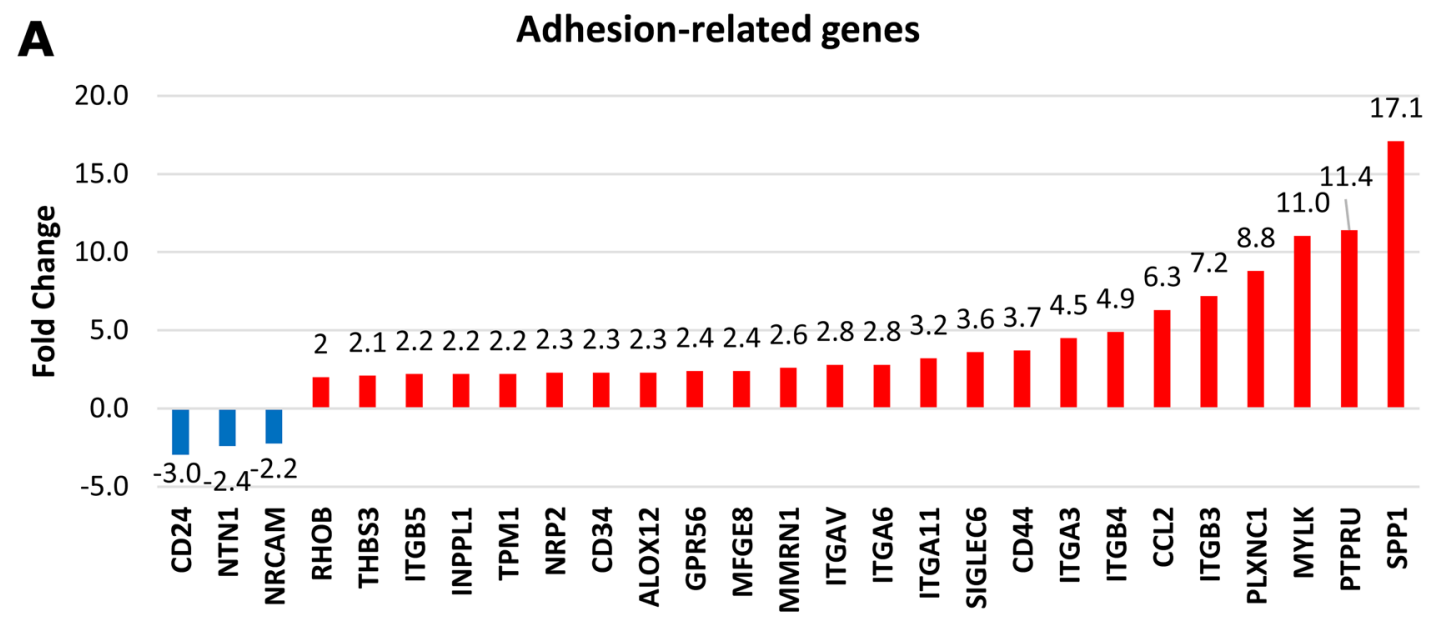

B

Stemness and differentiation regulation-related genes

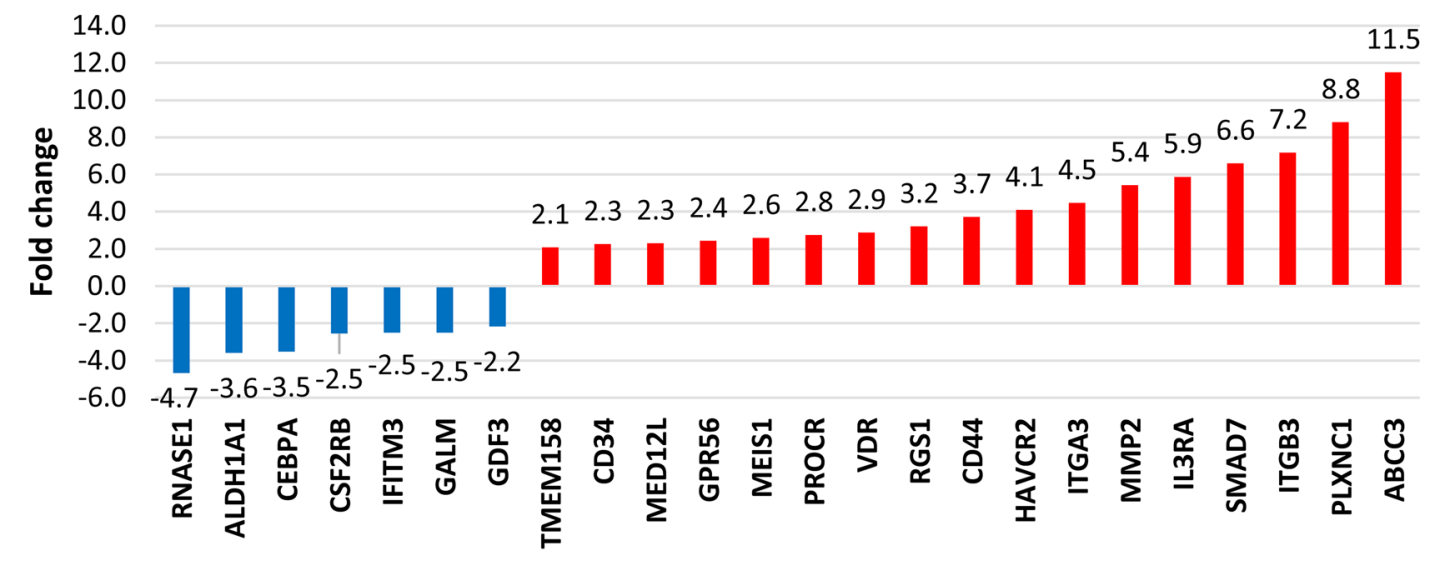

C

Tumour supressors and proliferation regulator genes

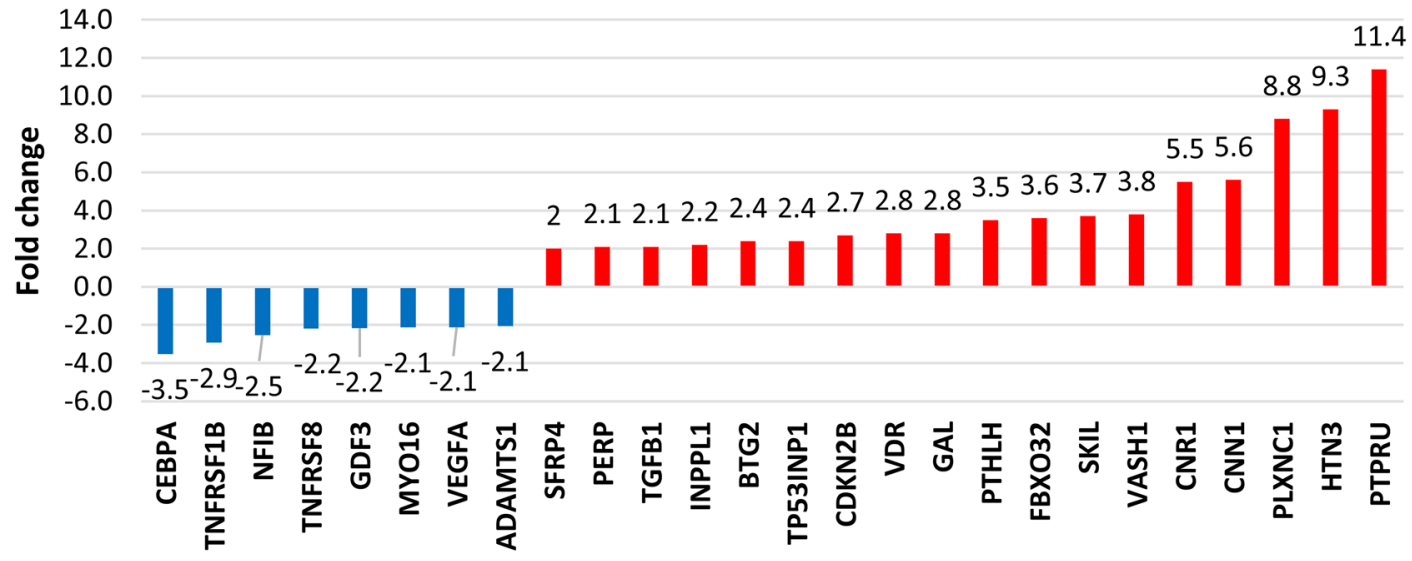

Figure 3: Biologically related groups of genes in dormant TF-1a cells. Mean values for fold upregulation (red bars) or downregulation (blue bars). 
potential therapeutic target in AML patients [19]. We therefore looked for the presence of osteopontin in primary AML patient material. Osteopontin protein was detected in the blast cell cytoplasm of both presentation and posttreatment BM biopsies from 7/7 patients (patient details in Supplementary Table 6). 2 of the biopsies showed stronger OPN expression in the cytoplasm of blasts adjacent to the bone trabeculae in comparison to those further from this area of the BM (Figure 5A). The other 5 cases showed a similar pattern of OPN expression regardless the anatomical localization of the leukaemia cells (e.g. Supplementary Figure 5). We also measured SPP1 message in 13 primary AML mononuclear cell isolates. In 10/13, SPP1 expression was undetectable (Supplementary Figure 6), strongly suggesting the necessity for exogenous factors present in the bone marrow microenvironment such as TGF $\beta 1$ to induce expression. Indeed SPP1 expression was induced by in vitro culture with TGF $\beta 1$ in $5 / 5$ samples (Figure 5B).

\section{Protein and functional validation of adhesion proteins in AML cells}

As genes involved in integrin-mediated signalling and adhesion were markedly enriched in the signature of dormant AML cells, we further characterised the most upregulated integrin - integrin beta 3 (ITGB3, CD61) and its binding partner integrin alpha $\mathrm{v}$ (ITGAV, CD51). We found upregulation of CD61 $(p=0.01)$ and CD51 protein expression $(\mathrm{p}=0.005)$ in the dormancy-enriched cells (Figure 6A). CD44, a gene found in the dormancy expression profile which interacts with ITGB3 and osteopontin to mediate adhesion and signalling (reviewed in [20] and [21]), was also upregulated at the protein level $(\mathrm{p}=0.01)$.

We also examined the adhesive properties of the dormancy-enriched TF-1a cells (Figure 6B), which demonstrated significantly enhanced adhesion to the stromal cell line HS-5 $(\mathrm{p}=0.03)$. Dormant cells were also more adherent than cycling cells to immobilised vitronectin (fold increase $2.5 ; \mathrm{p}=0.02$ ) and hyaluronic acid (fold increase $=2.4 ; \mathrm{p}=0.02$ ), (ligands of integrin B3 and CD44 respectively). As expected from the literature on this topic, fibronectin elicited strong adhesion [22], but this was not increased in dormant cells.

\section{Molecular signatures of dormancy in patient samples}

Publically available data from the Cancer Genome Atlas (TCGA) [23, 24] on 149 cases of AML (excluding patients with a $t(15 ; 17)$ translocation, but comprising all other patients with documented outcome data) was studied to determine whether there is a particular subset of AML patients with a strong intrinsic dormancy signature. Using unsupervised hierarchical clustering, we selected the 240 upregulated and 136 downregulated genes identified in our model, from which we mapped five clusters of genes and four clusters of patients (Figure 7A). A fifth patient cluster comprising a single case was excluded from the analysis. Using Fisher's exact test we determined significant enrichment for adhesion in gene cluster 5

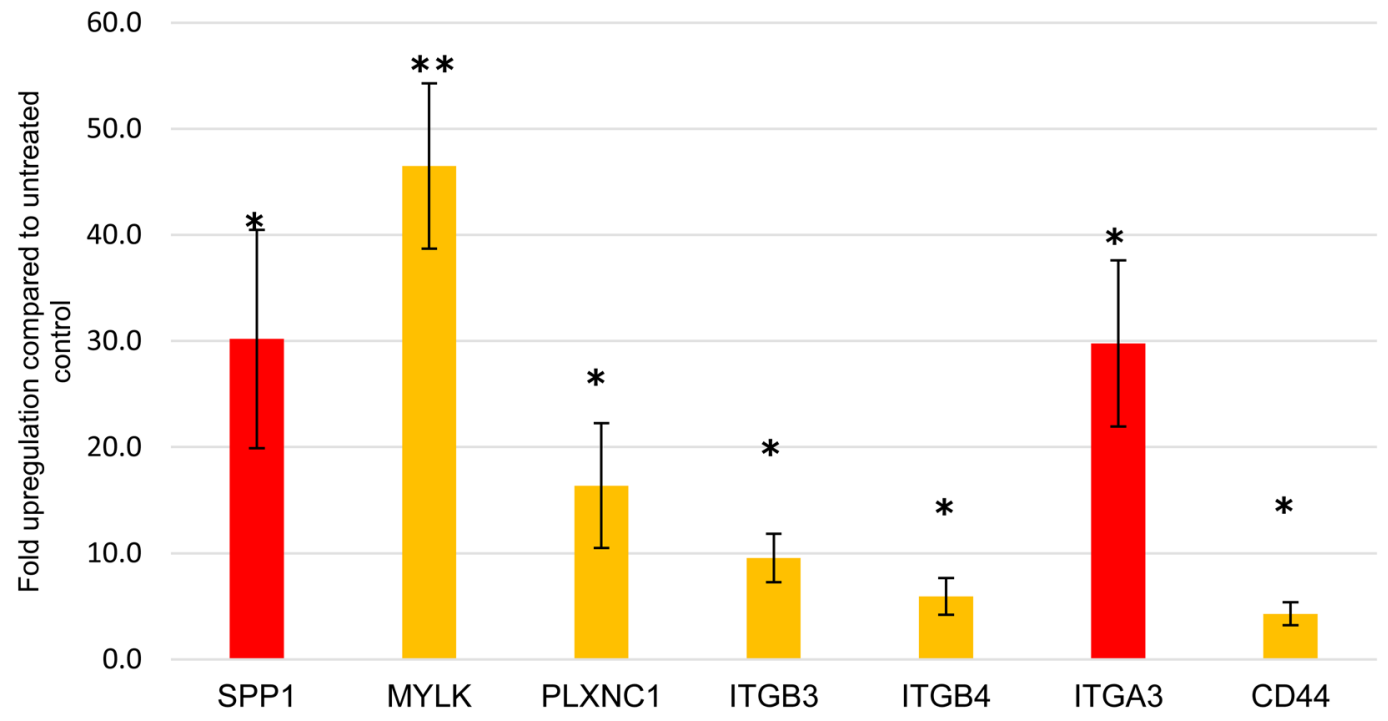

Figure 4: qPCR validation. Expression of the 7 top significantly upregulated adhesion-related genes in dormant TF-1a cells. SPP1 and ITGA3 genes are highlighted in red as their baseline expression was negligible, in contrast to the other genes where the increase was indicative of upregulation. Mean $+/$ - SD of three independent experiments. ${ }^{*} \mathrm{p}$ value $<0.05,{ }^{* *} \mathrm{p}$ value $<0.01$. 
A
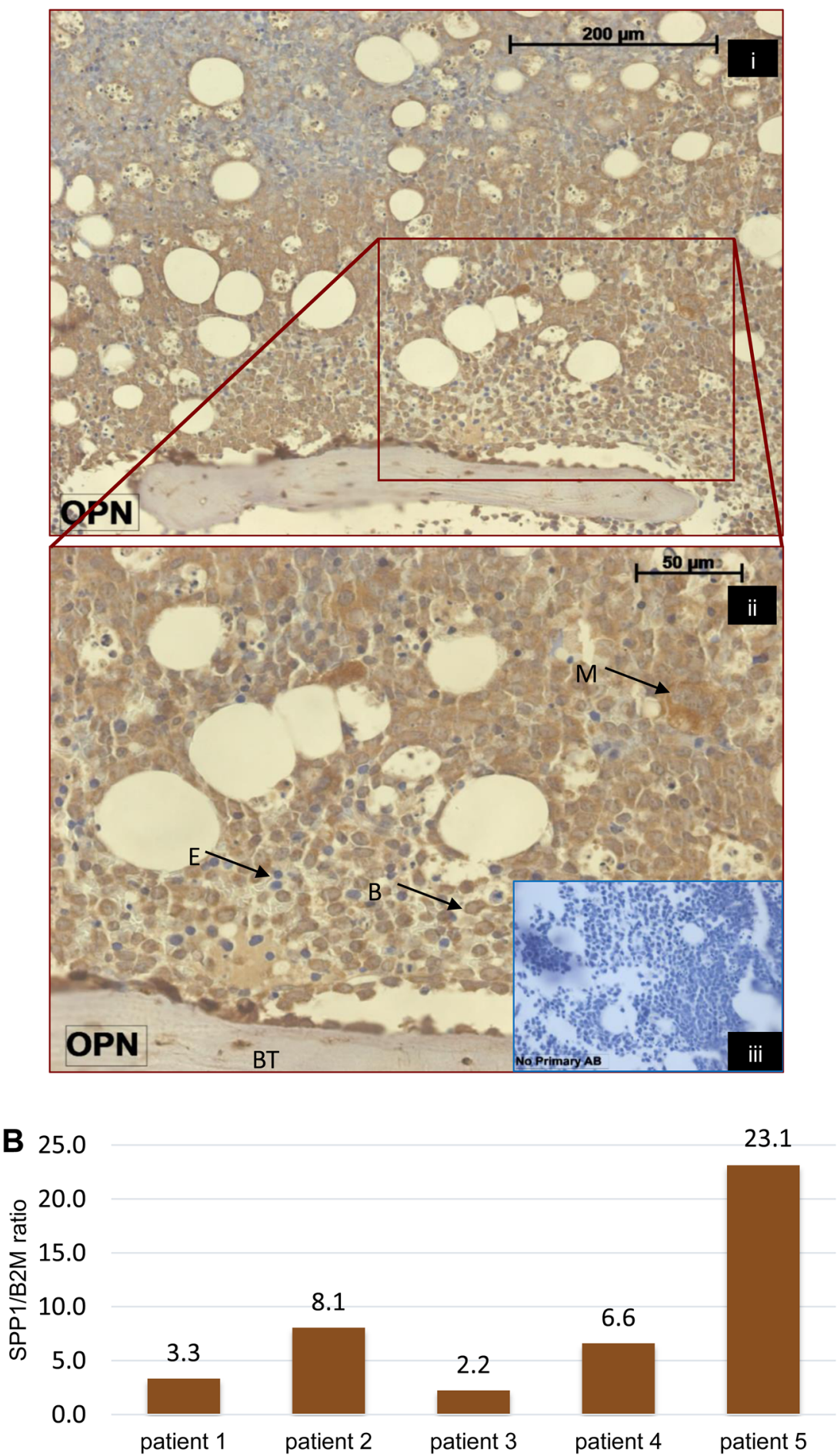

Figure 5: Osteopontin expression in AML patients. (A) Osteopontin expression in a bone marrow biopsy from an AML patient. Picture (ii) shows magnification of the rectangular area from picture (i) to illustrate the cytoplasmic expression in leukemic blasts. B, blast. BT, bone trabecula. E, erythroid cell. M, megakaryocyte. (iii) No primary antibody control. (B) SPP1 expression in primary AML cells in response to 3 day in vitro culture with $4 \mathrm{ng} / \mathrm{ml}$ TGF $\beta 1$. SPP1 message was measured by qPCR in 5 samples. Bars represent fold upregulation of SPP1:B2M ratio compared to untreated controls. 
$(\mathrm{P}=0.02)$, for stemness in gene cluster $3(\mathrm{P}=0.033)$ and for tumour suppressors in both gene cluster $4(\mathrm{P}=0.009)$ and cluster $5(\mathrm{P}=0.03)$ (Supplementary Table 7$)$. The four patient clusters were found to have significantly different proportions of highly expressed (>median) dormancy genes $(1<2<3<4)$. The overall survival of intensively treated patients $(n=127)$ was significantly worse in the cluster with the highest number of dormancy genes upregulated, i.e. patient cluster $4(\mathrm{P}=0.047$, Figure $7 \mathrm{~B})$. This patient cluster contained a low proportion of FLT3 mutations $(\mathrm{P}=0.051)$. It also contained all $6 \mathrm{FAB}$ M6 and M7 cases, but was not enriched for a particular cytogenetic risk group, age or mutation in NPM1 (Supplementary Table 8). Intensively treated patients were dichotomised for one year survival. After excluding patients still alive but censored at less than one year, 106 patients remained in the dataset (61 alive, 45 dead). In this group the ten most differentially over-expressed genes in patient cluster 4 were entered as potential predictors into multivariate (backward conditional) analysis. (Where there was more
A (i)
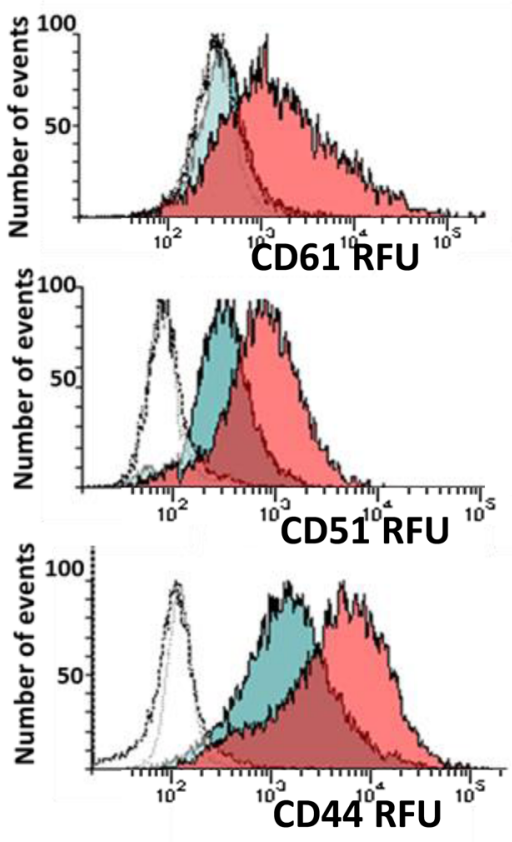

(ii)

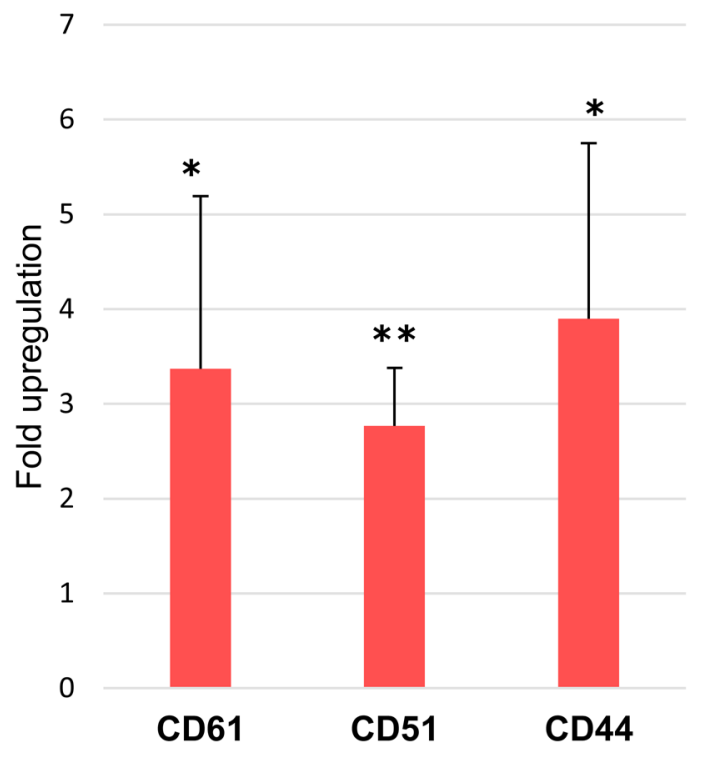

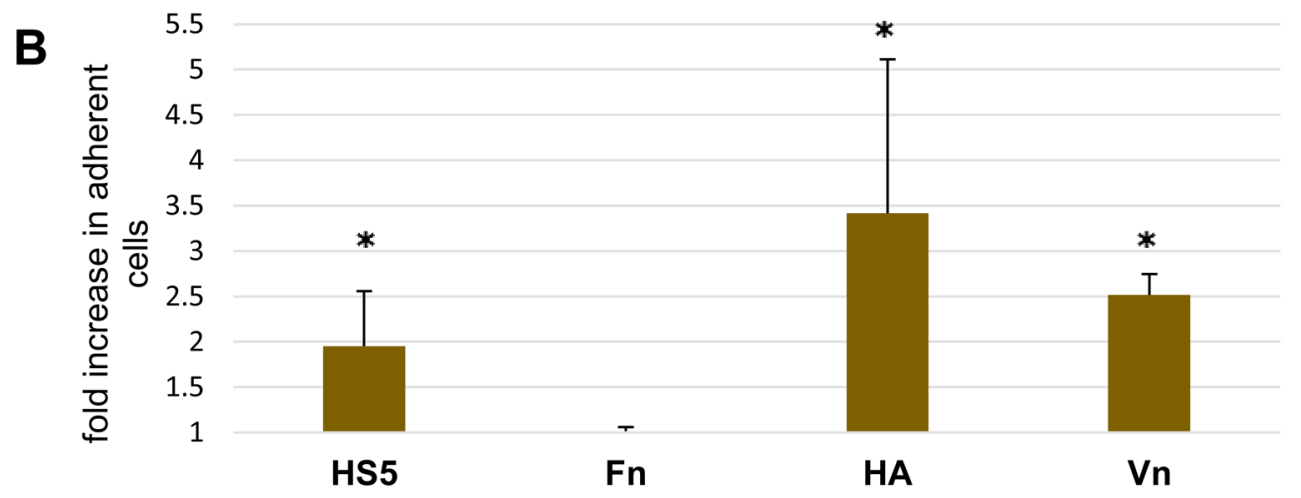

Figure 6: Adhesion molecule expression and in vitro adhesion of dormant TF-1a cells. (A) (i) Flow cytometric histograms illustrating CD61, CD51 and CD44 RFU (relative fluorescence units) in cycling TF-1a (blue-filled histogram), and dormant cells (pinkfilled histogram). Unfilled histograms represent isotype control fluorescence (in the case of CD61, the blue-filled histogram almost completely overlaps the isotype control). (ii) Summary plot (Mean + SD) for 3-6 independent assays. (B) The ratio of treated to untreated cells adherent to HS-5 stromal cells and to plates coated with fibronectin (Fn), hyaluronic acid (HA) or vitronectin (Vn), (Mean + SD for 3-5 independent assays). ${ }^{*}=$ p value $<0.05,{ }^{* *}=$ p value $<0.01$. 
than one probe per gene, only genes overexpressed in cluster 4 with at least 3 out of 4 probes were evaluated.) Expression levels of ITGB3, IL6ST and PTH2 were found to be significant prognostic factors of 1 year survival.
Cytogenetic risk group, age and the presence of FLT3-ITD and NPM1 mutations were entered (Supplementary Table 9 ), but were not found in the final model.

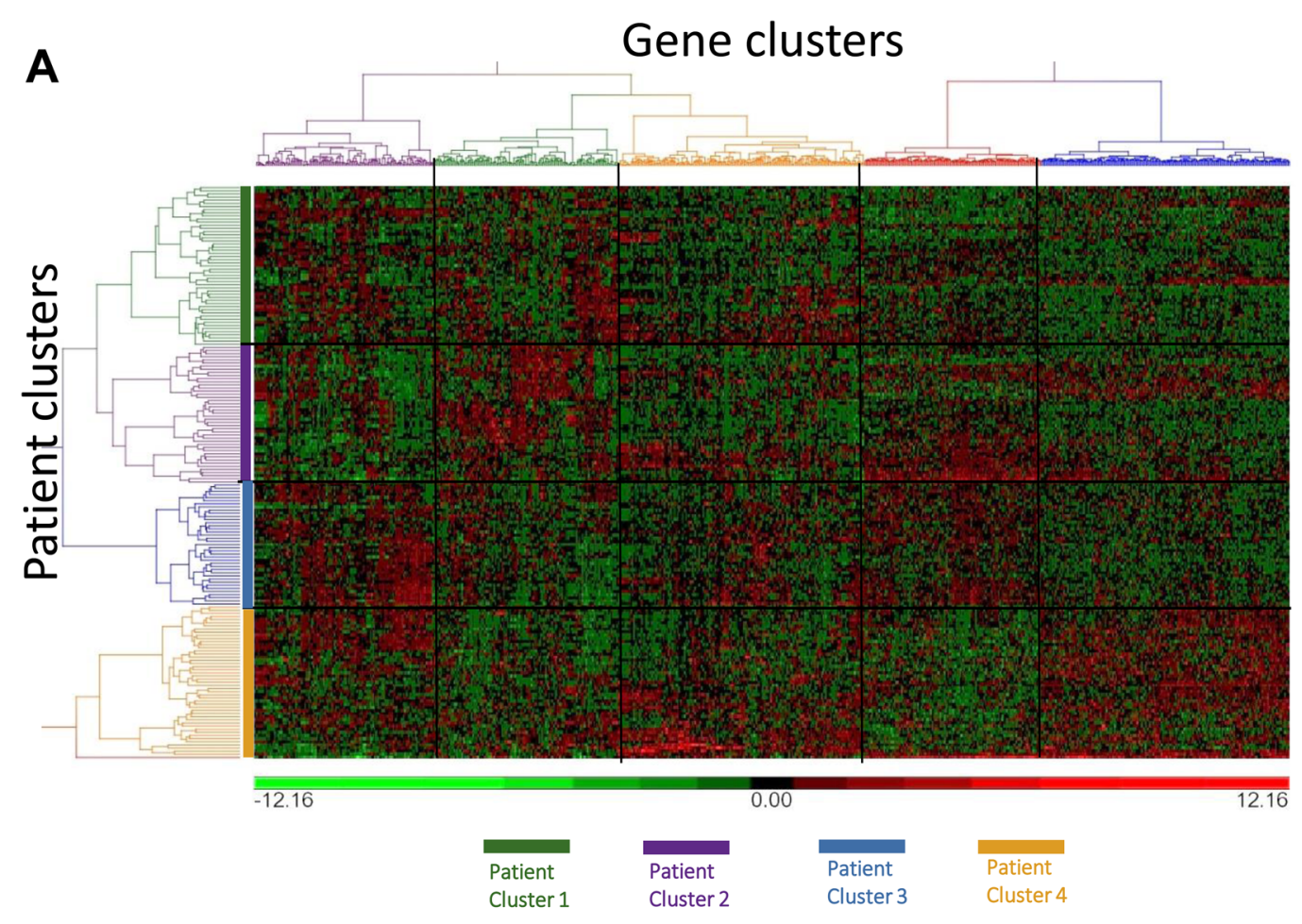

B

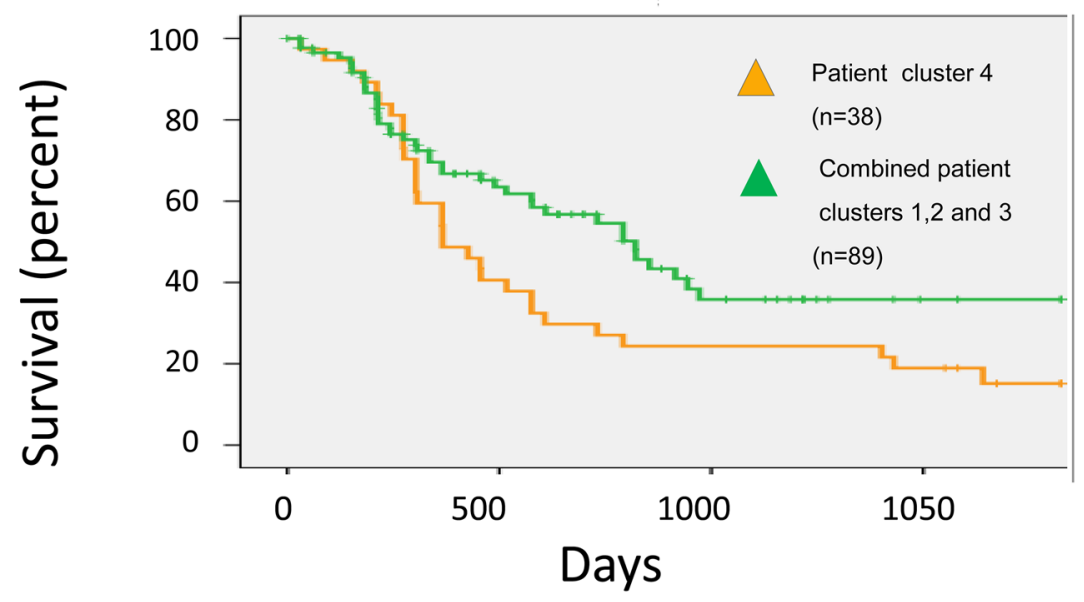

\begin{tabular}{|c|c|c|c|}
\hline & Chi-Square & df & Sig. \\
\hline $\begin{array}{c}\text { Log Rank } \\
\text { (Mantel- } \\
\text { Cox) }\end{array}$ & 3.959 & 1 & .047 \\
\hline
\end{tabular}

Figure 7: Dormancy signatures in TCGA patient samples. Analysis of samples from TCGA LAML database, which included 778 probes for 341/376 genes (240 upregulated and 136 downregulated) of the dormant TF-1a cell signature. (A) Un-supervised hierarchical clustering of the probes in 149 AML patient samples. (B) Survival curve of AML patients from Patient Cluster 4 (gold line) compared to the combined Patient Clusters 1, 2 and 3 (green line). 


\section{DISCUSSION}

The establishment of an in vitro model of dormancy in AML cells was achieved by exploiting two prominent features of the dormant LIC niche in the bone marrow endosteal region, i.e. TGF $\beta 1$ production and low perfusion. TGF $\beta 1$ and rapamycin maintained excellent cell viability. In contrast, serum withdrawal, the most common approach to dormancy induction in suspension culture, exacts a heavy toll on leukaemia cell viability that might overshadow pathways of dormancy maintenance [8]. Our choice of three day cell conditioning with TGF $\beta 1$ and rapamycin before GEP was informed by work documenting many differences between transient (induction of dormancy) and long-term (dormancy maintenance) gene expression profiles in somatic cells $[25,26]$. Our work focuses on consequences of a 3-day exposure to dormancy inducers and gives time for an equilibrium to be established between oncogene-driven growth and niche-driven quiescence, allowing us to describe likely characteristics of the chemoresistant LIC in the niche. The up-regulation of many genes in dormant TF1a cells despite the decrease in total RNA content indicates that dormancy is not merely an inhibition of proliferation or exit from the cell cycle, but is a phenomenon associated with active biological processes.

Upregulation of adhesion-related genes predominated in our model, and adhesion to bone marrow stromal cells, vitronectin and hyaluronic acid was also documented, supporting a role for recruitment and retention in specific microenvironments as a dominant characteristic of dormant LIC. Proliferating HSC and LSC display impairment of engraftment and reconstitution ability if compared to dormant counterparts $[27,28]$. Enrichment for cell adhesion molecules has been documented in the HSC quiescence signature [29].

The most up-regulated gene in the dormancy signature was the osteopontin-coding gene SPP1. Osteopontin can function as adhesion protein, cytokine or chemokine and is implicated in HSC migration and self-renewal [30]. In a study of ALL cells, osteopontin caused the cells to exit the cell cycle and rendered them resistant to chemotherapy in vivo. The study did not identify a cell cycle effect for osteopontin in vitro and the authors concluded that osteopontin's role was likely to be in regulating the homing of the leukaemia cells to the dormancy-inducing niche [31]. We demonstrated that osteopontin expression in AML blasts is dependent on tissue localisation, being high in biopsy material and low or negative in blasts from peripheral blood or bone marrow aspirates. Intracellular osteopontin can act as a bridging molecule for cytoskeletal re-arrangement and signal transduction $[32,33]$. The cytoskeleton is likely affected by the increase in MYLK, which was the second most upregulated gene in our model. MYLK codes for a myosin light chain kinase that phosphorylates the microfilament protein NMM-II. MYH9, an isoform of NMM-II, is also upregulated in our model. This pathway is involved in sensing mechanical inputs from the extracellular environment and their transduction into intracellular signals and has many roles in the bone marrow niche [34]. MYLK overexpression has been reported in other models of dormancy initiation [26] and maintenance [25].

ITGB3 is an essential molecule for leukaemia cell propagation [17]. Its knockdown results in impairment of LSC homing (specifically to the bone marrow endosteal surface), downregulation of an LSC transcriptional programme, and induced differentiation [17]. ITGB3 is upregulated in the $\mathrm{CD} 34^{+} \mathrm{CD} 38^{-}$blast subset [35] and has been implicated in chemoresistance [36]. Osteopontin can augment ITGB3-mediated spreading and signal transduction [20].

A critical feature of the dormant cell is resistance to differentiation [25]. In this context GEP showed upregulation of PLXN1, MMP2, GRP-56, TIM3, MEIS1 and its target RGS1, and ITGA6, all previously associated with a stem or multipotent progenitor stage of normal haematopoiesis [37], and the model also showed downregulation of differentiation associated genes CEBPA and CSF2RB. Several genes upregulated in the TF1a dormancy model have been described in leukaemia initiating cells, but appear not to be crucial for maintenance of normal HSCs, e.g. CD44 [18], ITGB3 [17], TIM3 (HAVCR2) [38] and IL3RA [39].

In addition to adhesion and stemness/inhibition of differentiation molecules we also documented tumour suppressor gene upregulation in TF-1a cells induced to dormancy (Figure 3). Strikingly, the only canonical cell cycle regulator upregulated in the model was the tumour suppressor CDKN2B (the cyclin-dependent kinase inhibitor p15). This gene is known to be epigenetically regulated, and is frequently mutated with a poor prognostic impact in AML [40]. In preliminary work we noted a transient induction of p57 by TGF $\beta 1$ (data not shown), which had disappeared by 24 hours. This reinforces the point made above that initiation and maintenance of dormancy can be characterised by largely different transcriptional programs. BTG2 upregulation may be a common dormancy feature. Classified as a tumour suppressor [41], it has also been documented to be overexpressed in somatic dormant and sublethally damaged cells [42].

This study focused on the profile of dormancy induced by extrinsic factors. In the case of SPP1/ osteopontin, we documented strong expression only in bone marrow biopsies or mononuclear cell isolates that had been cultured with TGF $\beta 1$. Nevertheless it was interesting to establish that TCGA primary AML samples have varied expression of dormancy signature genes and that these distributed into clusters unrelated to cytogenetic risk group. ITGB3 (discussed above) was upregulated in 
the dormancy model and also associated with poor one year survival in TCGA samples.

In this study, we demonstrated an in vitro approach mimicking key attributes of the LIC niche to characterize dormancy in $\mathrm{CD}^{+} 4^{+} \mathrm{CD} 38^{-}$AML cells. Genes identified in this model are candidates for investigations to establish potential targets for rooting out dormant AML cells.

\section{MATERIALS AND METHODS}

\section{AML cell lines and cell culture}

TF-1a cells were from The European Collection of Animal Cell Culture (Salisbury, UK) and were cultured in RPMI-1640 with 10\% FCS and glutamine. Following treatments, cells were counted flow cytometrically using an internal standard as described [43]. Testing to authenticate the cell line was performed at the last passage of each thawed batch using multiplex short tandem repeat analysis (Powerplex 16, Promega, Southampton, UK). Mycoplasma testing was carried out routinely using the Mycoalert mycoplasma detection kit (Lonza, Rockland, USA) and following the manufacturer's instructions.

\section{Patient cells}

The investigation was conducted on samples obtained with informed consent in accordance with ethical approval (Nottingham Research Ethics Committee 1) and Declaration of Helsinki and according to international guidelines and has been approved by the authors' institutional review board.

\section{Indirect immunofluorescence assay for FOXO3a}

Unmanipulated and TGF $\beta 1$-treated TF-1a cells were allowed to adhere on Poly-D-Lysine (PDL, p6407 Sigma)coated glass coverslips. They were stained with the 75D8 anti-FOXO3A antibody from Cell Signalling Technologies. Images were acquired using an Olympus fluorescence microscope and visualised with ImageJ software.

\section{Immunohistochemistry analysis of human bone marrow biopsies}

The expression of osteopontin (OPN) was investigated by immunohistochemistry (IHC) analysis of formalin-fixed paraffin-embedded BM biopsy sections using standard procedures with mouse anti-human monoclonal anti-OPN (ab166709; abcam) and the X-Cell Plus Universal Polymer horseradish peroxidase (MPXCP-U25; Menarini Diagnostics) detection system.

\section{Flow cytometry-based assays}

Flow cytometry analyses were carried out using the FACS Canto II (BD Biosciences) with Diva software.
Surface marker immunophenotyping was carried out using fluorochrome-conjugated anti-human monoclonal antibodies or isotype controls (BD Biosciences). The ALDEFLUOR $^{\mathrm{TM}}$ reagent kit (Stem Cell Technology $\# 01700$ ) was used to measure the intracellular activity of aldehyde dehydrogenase (ALDH). Cell viability was measured using Annexin V labelling (Trevigen Annexin $\mathrm{V}$ kit, \#4830-250-K). Mouse anti-human anti-Ki-67FITC (\#556026; BD Pharmingen, Oxford, UK) was used for detecting the nuclear protein Ki-67 in fixed and permeabilized AML cells. The protocol was based on a previously published method [44].

\section{Adhesion to cells or to immobilised molecular substrates assays}

HS-5 stromal cells [45] (American Type Culture Collection) were grown in DMEM with $10 \%$ FCS. Untreated and treated TF-1a cells were co-incubated with confluent HS-5 for three hours and detached by trypsinisation. TF-1a cells were identified and counted as described (Supplementary Figure 7).

96 well plates were coated with $10 \mu \mathrm{g} / \mathrm{ml}$ fibronectin, $10 \mu \mathrm{g} / \mathrm{ml}$ vitronectin or $1 \mathrm{mg} / \mathrm{ml}$ hyaluronic acid for 2 hours at $37^{\circ} \mathrm{C}$, rinsed twice in PBS and dried overnight. TF-1a cells were allowed to attach for three hours and non-adherent cells were removed by washing with warm PBS. Attached cells were counted with a light microscope fitted with a wire grid $(0.9 \mathrm{X} 0.9 \mathrm{~mm}$ squares, quadruplicate plates).

\section{Real-time quantitative polymerase chain reaction $(\mathrm{qPCR})$ assay}

Quantitative PCR was performed as previously described [46] using primer sequences as listed in Supplementary Table 10 and standardised with $\beta 2$ microglobulin (B2M) [47].

\section{Global human genome gene expression profile (GEP) assay}

RNA was processed according to the manufacturer's protocol using the Agilent 2100 Bioanalyzer and Human Gene 2.1 Array Strips (\#902114; Affymetrix) with the microarray system GeneAtlas from Affymetrix.

\section{Data analysis}

GEP data was analysed using Partek Genomics Suite 6.6 software. For the analysis of patient outcomes and groupings, the TCGA LAML data set GSE68833 was downloaded from the Gene Expression Omnibus. Hierarchical clustering, using the Ward's method was done with the Partek software. Additional analyses 
were performed using the Statistical Package for Social Sciences, version 23 (SPSS, Chicago, IL, USA).

\section{Abbreviations}

ALDH: aldehyde dehydrogenase; ALL: acute lymphoblastic leukaemia; AML: acute myeloid leukaemia; B2M: beta 2 microglobulin; BM: bone marrow; BTG2: $\mathrm{B}$ cell translocation gene 2; CDKN2B: cyclin-dependent kinase inhibitor 2B; CEBPA: CCAT enhancer binding protein alpha; CSF2RB: colony stimulating factor 2 receptor beta; DMEM: Dulbecco Modified Eagle Medium; FAB: French American British; FACS: fluorescence activated cell scanning; FCS: foetal calf serum; FDR: false discovery rate; FITC: fluorescein isothiocyanate; FLT3: fms-related tyrosine kinase 3; FOX03A: forkhead box 03A; GEP: gene expression profiling; GO: gene ontology; GRP-56: G protein-coupled receptor 56; HSC: haematopoietic stem cells; IL3RA: interleukin 3 receptor alpha; IHC: immunohistochemistry; ITGB3: integrin beta 3; ITGA6: integrin alpha 6; ITGAV: integrin alpha v; IL6ST: interleukin 6 signal transducer; KEGG: Kyoto Encyclopaedia of Genes and Genomes; LIC: leukaemiainitiating cells; MEIS1: myeloid ecotropic viral integration site 1; MMP2: matrix metalloproteinase 2; MTOR: mammalian target of rapamycin; MYH9: myosin heavy chain 9; MYLK: myosin light chain kinase; NPM1: nucleophosmin 1; OPN: osteopontin; PBS: phosphate buffered saline; PCR: polymerase chain reaction; PLXN1: plexin A1; PTH2: parathyroid hormone 2; RGS1: regulator of G-protein signalling 1; RNA: ribonucleic acid; RPMI: Roswell Park Memorial Institute; SPP1: secreted phosphoprotein 1; TCGA: the cancer genome atlas; TGF $\beta 1$; transforming growth factor beta 1; TIM3: T cell immunoglobulin and mucin domain 1

\section{Author contributions}

MGA participated in designing the study, performed, and analysed experiments and drafted the manuscript.

GB performed and analysed experiments

MC performed and oversaw experiments and edited the manuscript.

STM oversaw experiments and edited the manuscript.

KIM performed, oversaw and analysed experiments and edited the manuscript.

NHR participated in the design and co-ordination of the study and contributed primary AML samples.

CHS performed, oversaw and analysed experiments and edited the manuscript.

MP participated in designing the study, performed, oversaw and analysed experiments and edited the manuscript.

All authors read and approved the final manuscript

\section{ACKNOWLEDGMENTS}

We thank the Iraqi ministry of higher education and scientific research for financial support of Dr Al-Asadi.

\section{CONFLICTS OF INTEREST}

The authors declare no conflicts of interest.

\section{GRANT SUPPORT}

Funding was obtained from the Nottinghamshire Leukaemia Appeal for Dr Seedhouse and from Leukaemia and Lymphoma NI (LLNI) to Dr Mills.

\section{REFERENCES}

1. Saito Y, Uchida N, Tanaka S, Suzuki N, TomizawaMurasawa M, Sone A, Najima Y, Takagi S, Aoki Y, Wake A, Taniguchi S, Shultz LD, Ishikawa F. Induction of cell cycle entry eliminates human leukemia stem cells in a mouse model of AML. Nat Biotechnol. 2010; 28:275-280. https:// doi.org/10.1038/nbt.1607.

2. Ishikawa F, Yoshida S, Saito Y, Hijikata A, Kitamura H, Tanaka S, Nakamura R, Tanaka T, Tomiyama H, Saito N, Fukata M, Miyamoto T, Lyons B, et al. Chemotherapyresistant human AML stem cells home to and engraft within the bone-marrow endosteal region. Nature biotechnology. 2007; 25:1315-1321.

3. Kunisaki Y, Bruns I, Scheiermann C, Ahmed J, Pinho S, Zhang D, Mizoguchi T, Wei Q, Lucas D, Ito K, Mar JC, Bergman A, Frenette PS. Arteriolar niches maintain haematopoietic stem cell quiescence. Nature. 2013; 502:637-643. https://doi.org/10.1038/nature12612.

4. Winkler IG, Barbier V, Wadley R, Zannettino AC, Williams S, Levesque JP. Positioning of bone marrow hematopoietic and stromal cells relative to blood flow in vivo: serially reconstituting hematopoietic stem cells reside in distinct nonperfused niches. Blood. 2010; 116:375-385. https://doi. org/10.1182/blood-2009-07-233437.

5. Fingar DC, Blenis J. Target of rapamycin (TOR): an integrator of nutrient and growth factor signals and coordinator of cell growth and cell cycle progression. Oncogene. 2004; 23:3151-3171. https://doi.org/10.1038/ sj.onc. 1207542.

6. Jewell JL, Guan KL. Nutrient signaling to mTOR and cell growth. Trends Biochem Sci. 2013; 38:233-242. https://doi. org/10.1016/j.tibs.2013.01.004.

7. Huang J, Nguyen-McCarty M, Hexner EO, DanetDesnoyers G, Klein PS. Maintenance of hematopoietic stem cells through regulation of Wnt and mTOR pathways. Nat Med. 2012; 18:1778-1785. https://doi.org/10.1038/ nm.2984. 
8. Pallis M, Burrows F, Whittall A, Boddy N, Seedhouse C, Russell N. Efficacy of RNA polymerase II inhibitors in targeting dormant leukaemia cells. BMC Pharmacol Toxicol. 2013; 14:32. https://doi.org/10.1186/2050-6511-14-32.

9. Kim JK, Jung Y, Wang J, Joseph J, Mishra A, Hill EE, Krebsbach PH, Pienta KJ, Shiozawa Y, Taichman RS. TBK1 regulates prostate cancer dormancy through mTOR inhibition. Neoplasia. 2013; 15:1064-1074.

10. Blank U, Karlsson S. TGF-beta signaling in the control of hematopoietic stem cells. Blood. 2015; 125:3542-3550. https://doi.org/10.1182/blood-2014-12-618090.

11. Law BK, Chytil A, Dumont N, Hamilton EG, WaltnerLaw ME, Aakre ME, Covington C, Moses HL. Rapamycin potentiates transforming growth factor beta-induced growth arrest in nontransformed, oncogene-transformed, and human cancer cells. Mol Cell Biol. 2002; 22:8184-8198.

12. Brenner AK, Andersson Tvedt TH, Bruserud O. The complexity of targeting PI3K-Akt-mTOR signalling in human acute myeloid leukaemia: the importance of leukemic cell heterogeneity, neighbouring mesenchymal stem cells and immunocompetent cells. Molecules. 2016; 21:E1512. https://doi.org/10.3390/molecules21111512.

13. Chen C, Liu Y, Liu R, Ikenoue T, Guan KL, Zheng P. TSCmTOR maintains quiescence and function of hematopoietic stem cells by repressing mitochondrial biogenesis and reactive oxygen species. J Exp Med. 2008; 205:2397-2408. https://doi.org/10.1084/jem.20081297.

14. Batard P, Monier MN, Fortunel N, Ducos K, SansilvestriMorel P, Phan T, Hatzfeld A, Hatzfeld JA. TGF-(beta)1 maintains hematopoietic immaturity by a reversible negative control of cell cycle and induces CD34 antigen up-modulation. J Cell Sci. 2000; 113:383-390.

15. Naka K, Hoshii T, Muraguchi T, Tadokoro Y, Ooshio T, Kondo Y, Nakao S, Motoyama N, Hirao A. TGF-betaFOXO signalling maintains leukaemia-initiating cells in chronic myeloid leukaemia. Nature. 2010; 463:676-680. https://doi.org/10.1038/nature08734.

16. Gerber JM, Smith BD, Ngwang B, Zhang H, Vala MS, Morsberger L, Galkin S, Collector MI, Perkins B, Levis MJ, Griffin CA, Sharkis SJ, Borowitz MJ, et al. A clinically relevant population of leukemic CD34(+)CD38(-) cells in acute myeloid leukemia. Blood. 2012; 119:3571-3577. https://doi.org/10.1182/blood-2011-06-364182.

17. Miller PG, Al-Shahrour F, Hartwell KA, Chu LP, Jaras M, Puram RV, Puissant A, Callahan KP, Ashton J, McConkey ME, Poveromo LP, Cowley GS, Kharas MG, et al. In Vivo RNAi screening identifies a leukemia-specific dependence on integrin beta 3 signaling. Cancer Cell. 2013; 24:45-58. https://doi.org/10.1016/j.ccr.2013.05.004.

18. Jin L, Hope KJ, Zhai Q, Smadja-Joffe F, Dick JE. Targeting of CD44 eradicates human acute myeloid leukemic stem cells. Nat Med. 2006; 12:1167-1174.

19. Chen YB, Ren SM, Li SD, Du Z. Prognostic significance of osteopontin in acute myeloid leukemia: a meta-analysis.
Mol Clin Oncol. 2017; 7:275-280. https://doi.org/10.3892/ mco.2017.1302.

20. Weber GF. The metastasis gene osteopontin: a candidate target for cancer therapy. Biochim Biophys Acta. 2001; 1552:61-85.

21. Gimba ER, Tilli TM. Human osteopontin splicing isoforms: known roles, potential clinical applications and activated signaling pathways. Cancer Lett. 2013; 331:11-17. https:// doi.org/10.1016/j.canlet.2012.12.003.

22. Matsunaga T, Takemoto N, Sato T, Takimoto R, Tanaka I, Fujimi A, Akiyama T, Kuroda H, Kawano Y, Kobune M, Kato J, Hirayama Y, Sakamaki S, et al. Interaction between leukemic-cell VLA-4 and stromal fibronectin is a decisive factor for minimal residual disease of acute myelogenous leukemia. Nat Med. 2003; 9:1158-1165.

23. Cerami E, Gao J, Dogrusoz U, Gross BE, Sumer SO, Aksoy BA, Jacobsen A, Byrne CJ, Heuer ML, Larsson E, Antipin Y, Reva B, Goldberg AP, et al. The cBio cancer genomics portal: an open platform for exploring multidimensional cancer genomics data. Cancer Discov. 2012; 2:401-404. https://doi.org/10.1158/2159-8290.CD-12-0095.

24. Ley TJ, Miller C, Ding L, Raphael BJ, Mungall AJ, Robertson A, Hoadley K, Triche TJ Jr, Laird PW, Baty JD, Fulton LL, Fulton R, Heath SE, et al; Cancer Genome Atlas Research Network. Genomic and epigenomic landscapes of adult de novo acute myeloid leukemia. N Engl J Med. 2013; 368:2059-2074. https://doi.org/10.1056/NEJMoa1301689.

25. Coller HA, Sang L, Roberts JM. A new description of cellular quiescence. PLoS Biol. 2006; 4:e83. https://doi. org/10.1371/journal.pbio.0040083.

26. Liu H, Adler AS, Segal E, Chang HY. A transcriptional program mediating entry into cellular quiescence. PLoS Genet. 2007; 3:e91. https://doi.org/10.1371/journal. pgen.0030091.

27. Glimm H, Oh IH, Eaves CJ. Human hematopoietic stem cells stimulated to proliferate in vitro lose engraftment potential during their $\mathrm{S} / \mathrm{G}(2) / \mathrm{M}$ transit and do not reenter $\mathrm{G}(0)$. Blood. 2000; 96:4185-4193.

28. Guan Y, Gerhard B, Hogge DE. Detection, isolation and stimulation of quiescent primitive leukemic progenitor cells from patients with acute myeloid leukemia (AML). Blood. 2003; 101:3142-3149.

29. Venezia TA, Merchant AA, Ramos CA, Whitehouse NL, Young AS, Shaw CA, Goodell MA. Molecular signatures of proliferation and quiescence in hematopoietic stem cells. PLoS Biol. 2004; 2:e301. https://doi.org/10.1371/journal. pbio.0020301.

30. Nilsson SK, Johnston HM, Whitty GA, Williams B, Webb RJ, Denhardt DT, Bertoncello I, Bendall LJ, Simmons PJ, Haylock DN. Osteopontin, a key component of the hematopoietic stem cell niche and regulator of primitive hematopoietic progenitor cells. Blood. 2005; 106:12321239. https://doi.org/10.1182/blood-2004-11-4422. 
31. Boyerinas B, Zafrir M, Yesilkanal AE, Price TT, Hyjek EM, Sipkins DA. Adhesion to osteopontin in the bone marrow niche regulates lymphoblastic leukemia cell dormancy. Blood. 2013; 121:4821-4831. https://doi.org/10.1182/ blood-2012-12-475483.

32. Zhu B, Suzuki K, Goldberg HA, Rittling SR, Denhardt DT, McCulloch CA, Sodek J. Osteopontin modulates CD44dependent chemotaxis of peritoneal macrophages through G-protein-coupled receptors: evidence of a role for an intracellular form of osteopontin. J Cell Physiol. 2004; 198:155-167. https://doi.org/10.1002/jcp.10394.

33. Inoue M, Shinohara ML. Intracellular osteopontin (iOPN) and immunity. Immunol Res. 2011; 49:160-172. https://doi. org/10.1007/s12026-010-8179-5.

34. Shin JW, Swift J, Ivanovska I, Spinler KR, Buxboim A, Discher DE. Mechanobiology of bone marrow stem cells: from myosin-II forces to compliance of matrix and nucleus in cell forms and fates. Differentiation. 2013; 86:77-86. https://doi.org/10.1016/j.diff.2013.05.001.

35. Gal H, Amariglio N, Trakhtenbrot L, Jacob-Hirsh J, Margalit O, Avigdor A, Nagler A, Tavor S, Ein-Dor L, Lapidot T, Domany E, Rechavi G, Givol D. Gene expression profiles of AML derived stem cells; similarity to hematopoietic stem cells. Leukemia. 2006; 20:2147-2154.

36. Yi H, Zeng D, Shen Z, Liao J, Wang X, Liu Y, Zhang $\mathrm{X}$, Kong P. Integrin alphavbeta3 enhances beta-catenin signaling in acute myeloid leukemia harboring Fms-like tyrosine kinase-3 internal tandem duplication mutations: implications for microenvironment influence on sorafenib sensitivity. Oncotarget. 2016. https://doi.org/10.18632/ oncotarget.9617.

37. Ng SY, Yoshida T, Zhang J, Georgopoulos K. Genome-wide lineage-specific transcriptional networks underscore Ikarosdependent lymphoid priming in hematopoietic stem cells. Immunity. 2009; 30:493-507. https://doi.org/10.1016/j. immuni.2009.01.014.

38. Jan M, Chao MP, Cha AC, Alizadeh AA, Gentles AJ, Weissman IL, Majeti R. Prospective separation of normal and leukemic stem cells based on differential expression of TIM3, a human acute myeloid leukemia stem cell marker. Proc Natl Acad Sci U S A. 2011; 108:5009-5014. https:// doi.org/10.1073/pnas.1100551108.

39. Yalcintepe L, Frankel AE, Hogge DE. Expression of interleukin-3 receptor subunits on defined subpopulations of acute myeloid leukemia blasts predicts the cytotoxicity of diphtheria toxin interleukin-3 fusion protein against malignant progenitors that engraft in immunodeficient mice. Blood. 2006; 108:3530-3537. https://doi.org/10.1182/ blood-2006-04-013813.

40. De Braekeleer M, Douet-Guilbert N, De Braekeleer E. Prognostic impact of p15 gene aberrations in acute leukemia. Leuk Lymphoma. 2017; 58:257-265. https://doi. org/10.1080/10428194.2016.1201574.

41. Mao B, Zhang Z, Wang G. BTG2: a rising star of tumor suppressors (review). Int J Oncol. 2015; 46:459-464. https:// doi.org/10.3892/ijo.2014.2765.

42. Zhou T, Chou JW, Simpson DA, Zhou Y, Mullen TE, Medeiros M, Bushel PR, Paules RS, Yang X, Hurban P, Lobenhofer EK, Kaufmann WK. Profiles of global gene expression in ionizing-radiation-damaged human diploid fibroblasts reveal synchronization behind the G1 checkpoint in a G0-like state of quiescence. Environ Health Perspect. 2006; 114:553-559.

43. Pallis M, Syan J, Russell NH. Flow cytometric chemosensitivity analysis of blasts from patients with acute myeloblastic leukemia and myelodysplastic syndromes: the use of 7AAD with antibodies to CD45 or CD34. Cytometry. 1999; 37:308-313.

44. Jordan CT, Yamasaki G, Minamoto D. High-resolution cell cycle analysis of defined phenotypic subsets within primitive human hematopoietic cell populations. Exp Hematol. 1996; 24:1347-1355.

45. Roecklein BA, Torok-Storb B. Functionally distinct human marrow stromal cell lines immortalized by transduction with the human papilloma virus E6/E7 genes. Blood. 1995; 85:997-1005.

46. Pallis M, Abdul-Aziz A, Burrows F, Seedhouse C, Grundy M, Russell N. The multi-kinase inhibitor TG02 overcomes signalling activation by survival factors to deplete MCL1 and XIAP and induce cell death in primary acute myeloid leukaemia cells. Br J Haematol. 2012; 159:191-203. https:// doi.org/10.1111/bjh.12018.

47. Pallisgaard N, Clausen N, Schroder H, Hokland P. Rapid and sensitive minimal residual disease detection in acute leukemia by quantitative real-time RT-PCR exemplified by $\mathrm{t}(12 ; 21)$ TEL-AML1 fusion transcript. Genes Chromosomes Cancer. 1999; 26:355-365. 